\title{
Overcoming Statin Intolerance in Clinical Practice: An Enduring Effort
}

\author{
Furio Colivicchi $^{\mathrm{a}}$ Giuseppe Imperoli $^{\mathrm{b}}$ \\ ${ }^{\mathrm{a} C a r d i o l o g y}$ Division, Emergency Department, San Filippo Neri Hospital, Rome, Italy; ${ }^{\mathrm{b}}$ Internal Medicine Division, \\ Emergency Department, San Filippo Neri Hospital, Rome, Italy
}

Low-density lipoprotein cholesterol (LDL-C) reduction with statin therapy remains the cornerstone of lipidlowering intervention to reduce the risk of atherosclerotic cardiovascular disease [1]. Even if statins are generally well tolerated by the vast majority of patients, $20-30 \%$ of the patients with a clinical indication for such a therapy may show some form of intolerance leading to treatment disruption [2]. As a matter of fact, owing to side effects or adverse reactions, the rate of statin therapy discontinuation only 1 year after initiation may reach $40-60 \%[2,3]$.

In clinical practice, statin intolerance can be broadly defined as any adverse event and/or laboratory abnormality attributed to statin treatment and leading to its discontinuation [1-4]. In general, interruption of statin therapy due to laboratory abnormalities is less common, while most cases of intolerance are due to muscle complaints [1-4].

Pitavastatin is the most recent statin to receive regulatory approval with similar indications as to the other compounds of the same class [5]. Pitavastatin, as all other statins, inhibits HMG-CoA (3-hydroxy-3-methylglutaryl-coenzyme $\mathrm{A}$ ), thereby reducing LDL-C, Apo B, and triglycerides and slightly increasing high-density lipopro- tein cholesterol $[5,6]$. Differently from other statins, pitavastatin contains a cyclopropyl group that fits within the hydrophobic areas of the HMG-CoA reductase enzyme, partially explaining its potent inhibitory activities with a limited dosage (1-4 mg) [5, 6]. In fact, clinical studies have shown that pitavastatin has a three- to seven-fold greater potency than simvastatin and pravastatin [7].

Ezetimibe inhibits the absorption of cholesterol mediated by the sterol transporter Niemann-Pick C1-like-1 (NPC1L1) at the brush border of the small intestine [8]. The reduction in cholesterol absorption results in a decrease in LDL-C, with no significant effect on fat-soluble vitamins (vitamin A, D, and E) [8]. When used as monotherapy or in combination with statins, ezetimibe reduces LDL cholesterol by $15-22 \%[8,9]$. Consequently, in clinical practice, the association of ezetimibe with statins may represent a valuable option, allowing the achievement of significant reductions of LDL-C levels with a positive impact on cardiovascular outcomes [9]. In particular, the combination of pitavastatin and ezetimibe has proven both safe and effective in patients with a very high cardiovascular risk after an acute coronary syndrome [10].

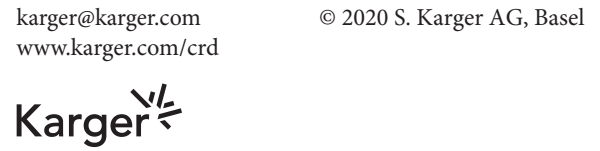




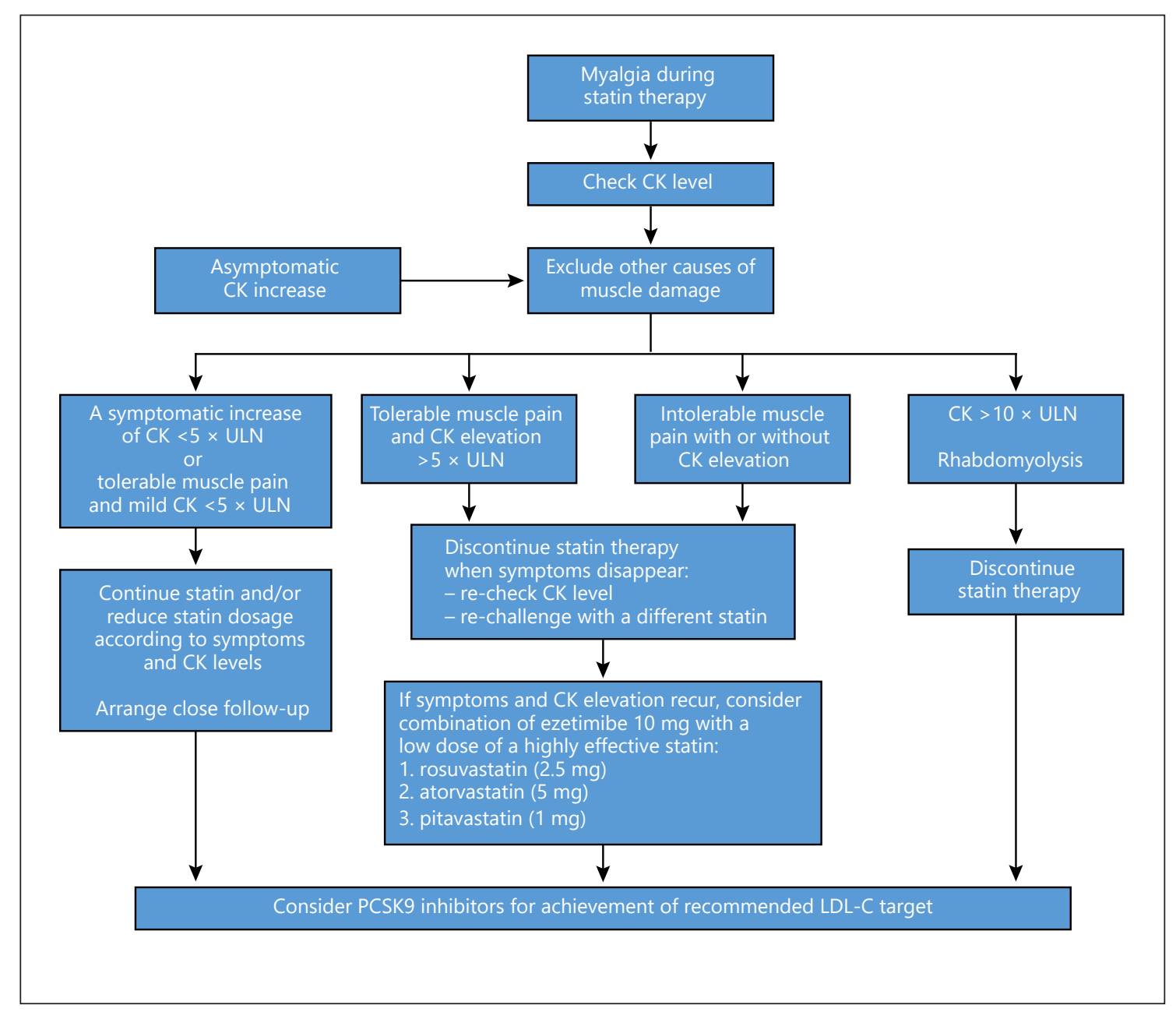

Fig. 1. Simplified critical pathway in patients with statin intolerance. CK, creatine kinase; LDL-C, low-density lipoprotein cholesterol; ULN, upper limit of normal.

In this issue of Cardiology, Christou et al. [11] describe the interesting case of a high-risk patient suffering severe muscle disturbances while on several different statin agents. In the end, a significant $40 \%$ reduction of LDL-C was achieved by low-dose pitavastatin $(1 \mathrm{mg})$ in combination with ezetimibe $10 \mathrm{mg}$, without any major muscle complaint.

Overall, the simple therapeutic strategy used in this case appears to be effective and appealing for practicing clinicians. A low dose of a highly effective statin in combination with ezetimibe may actually represent the standard of choice when facing persisting statin intolerance [2]. In fact, the synergic block of both hepatic cholesterol synthesis and intestinal absorption may contribute to a relevant LDL-C reduction [1]. In Figure 1 , a specific algorithm of intervention is outlined, which can be easily implemented in most cases of clinically relevant intolerance. In particular, the combination of low-dose pitavastatin (i.e., $1 \mathrm{mg}$ ) with ezetimibe may effectively reduce LDL-C by $35-50 \%[6,7]$, thereby allowing a significant containment of cardiovascular risk.

\section{Disclosure Statement}

The authors have no conflicts of interest to declare.

\section{Author Contributions}

Both authors have equally contributed to the manuscript. 


\section{References}

1 Mach F, Baigent C, Catapano AL, Koskinas KC, Casula M, Badimon L, et al.; ESC Scientific Document Group. 2019 ESC/EAS Guidelines for the management of dyslipidaemias: lipid modification to reduce cardiovascular risk. Eur Heart J. 2020 Jan;41(1):111-88.

2 Gulizia MM, Colivicchi F, Arca M, Abrignani MG, Perna GP, Mureddu GF, et al.; Italian Association of Hospital Cardiologists (ANMCO). ANMCO Position Paper: diagnostic-therapeutic pathway in patients with hypercholesterolaemia and statin intolerance. Eur Heart J Suppl. 2017 May;19 Suppl D:D5563.

3 Colivicchi F, Bassi A, Santini M, Caltagirone C. Discontinuation of statin therapy and clinical outcome after ischemic stroke. Stroke. 2007 Oct;38(10):2652-7.
4 Toth PP, Patti AM, Giglio RV, Nikolic D, Castellino G, Rizzo M, et al. Management of Statin Intolerance in 2018: Still More Questions Than Answers. Am J Cardiovasc Drugs. 2018 Jun;18(3):157-73.

5 Saito Y. Critical appraisal of the role of pitavastatin in treating dyslipidemias and achieving lipid goals. Vasc Health Risk Manag. 2009;5:921-36.

6 Baker WL, Datta R. Pitavastatin: a new 3-hydroxy-3-methylglutaryl coenzyme a reductase inhibitor for the treatment of hyperlipidemia. Adv Ther. 2011 Jan;28(1):13-27.

7 Saito Y. Pitavastatin: an overview. Atheroscler Suppl. 2011 Nov;12(3):271-6.

8 Sudhop T, Lütjohann D, Kodal A, Igel M, Tribble DL, Shah S, et al. Inhibition of intestinal cholesterol absorption by ezetimibe in humans. Circulation. 2002 Oct;106(15): 1943-8.
9 Savarese G, De Ferrari GM, Rosano GM, Perrone-Filardi P. Safety and efficacy of ezetimibe: A meta-analysis. Int J Cardiol. 2015 Dec;201:247-52.

10 Hagiwara N, Kawada-Watanabe E, Koyanagi $\mathrm{R}$, Arashi H, Yamaguchi J, Nakao K, et al. Low-density lipoprotein cholesterol targeting with pitavastatin + ezetimibe for patients with acute coronary syndrome and dyslipidaemia: the HIJ-PROPER study, a prospective, openlabel, randomized trial. Eur Heart J. 2017 Aug; 38(29):2264-76.

11 Christou GA, Mprikos SG, Christou KA, Christou MA, Christou EA, Nikas DN, et al. High Tolerability of Pitavastatin Therapy: A Case Report of Comparison with other Statins. Cardiology. DOI: 10.1159/000506394. 